\title{
Proposta de Técnicas de Controle da Erosão na rodovia PR-317 entre os Municípios de Floresta-PR e Peabirú-PR
}

Proposal for erosion control techniques on highway $P R-317$ between the cities of Floresta-PR and Peabirú-PR, Brazil (Calibre 12 - Itálico)

Propuesta de técnicas de control de la erosión en la carretera PR-317 entre las ciudades de Floresta-PR y Peabiru-PR (Calibre 12 - Itálico)

Karem Kiyomi Nakajima Graduação em Engenharia Civil, UTFPR, Brasil karemnakajima@gmail.com

Helton Rogério Mazzer

Professor Doutor, UTFPR, Brasil hmazzer@gmail.com

Eudes José Arantes

Professor Doutor, UTFPR, Brasil eudesarantes@utfpr.edu.br 


\section{RESUMO}

O objetivo do presente trabalho é abordar técnicas de controle de erosão visando reduzir o impacto ambiental através da vegetação adequada e o uso da Bioengenharia dos solos. Desta forma, foi possível realizar levantamento fotográfico e identificar o tipo de erosão e os respectivos agentes causadores da erosão. $O$ método da pesquisa foi fundamentado em um estudo de caso realizado às margens da PR-317 com levantamento de dados em campo e registrar áreas suscetíveis à erosão caracterizando sua forma e tipo de agente causador e apresentar métodos de contenção da erosão. Foi quantificado cada tipo de erosão e seu respectivo agente causador, seja por declividade, escoamento superficial, sulcos, ravinas e voçorocas. Um dos fatores a serem considerados é estabelecer critérios para o uso considerando a capacidade do solo e aplicar técnicas para a recuperação das áreas afetadas. Ao longo do trecho, observou-se grande índice de erosão tipo sulcos e alguns pontos mais agravantes tipo voçoroca. 0 escoamento da água da chuva e ausência de técnicas de drenagem foram os principais fatores contribuintes da erosão. O maior problema encontrado foi a falta de sistemas de contenção adequada devidos as obras de engenharia ao longo do trecho. Técnicas como hidro-semeadura, leivamentos, dissipadores de energia, sarjetas e descidas d'água foram utilizados para eliminar tais fatores e manter a boa absorção do solo e contribuir para a boa funcionalidade do pavimento.

PALAVRAS-CHAVE: Escoamento Superficial, erosão, agente causador da erosão. 


\section{INTRODUÇÃO}

A erosão, conhecida como um conjunto de processos que consiste na desagregação, composição e transporte de partículas de solo, pode ocorrer tanto nas camadas superficiais como na mais profunda, este processo e intensidade dependem, das condições climáticas, topografa do terreno e tipo de vegetação (GONÇALVES, 2002). O processo erosivo possui como agentes erosivos a chuva, o vento e a água (SALOMÃO E IWASA, 1995).

De acordo com Galeti (1979), existem diversos tipos de erosão na qual o agente causador é a água, alguns deles serão classificados como erosão laminar, em sulcos e subterrâneas (voçorocas).

Com o crescente avanço da construção civil, aumentou-se o grau de impacto ambiental modificando a estrutura inicial do solo. A prática da vegetação, juntamente com recursos da tecnologia, além de ser uma medida extremamente importante contra ações erosivas em áreas urbanas e rurais, é o fator primordial para a prevenção e contenção de erosão em taludes e encostas para preservação do meio ambiente, neste caso, é empregada a Bioengenharia dos solos, que através da análise da área afetada é empregada técnicas que recompõe a vegetação devolvendo a proteção natural do solo (GALAS, 2006).

Durante o crescimento e a evolução das obras na área da construção civil, prejudicou-se intensivamente a qualidade de absorção da água das chuvas juntamente com a vegetação existente que auxiliam no reforço mecânico das raízes que geram suporte aos taludes íngremes. De fato, a falta de absorção da água da chuva e da vegetação, tem provocado novos pontos de alagamento, que provêm da crescente impermeabilização do solo através do aumento significativo do volume pluvial e diminuição do amortecimento das quedas de água. Para isto, há necessidade de aplicação de uma série de medidas, entre elas, aplicação do projeto de técnicas de drenagem que possibilitam o controle de erosão através de dissipadores de energia à jusante que facilita o escoamento mais rápido e eficaz, o uso da vegetação que é um meio eficaz e totalmente sustentável e uso da hidro-semeadura, empregado por algumas empresas para melhorar a estabilidade dos taludes e prevenir contra erosão (GALAS, 2006).

Neste sentido, este trabalho visa apresentar algumas medidas preventivas para estabelecer melhorias na estabilidade dos taludes e propondo técnicas corretivas que auxiliam na proteção dos taludes e tipo de vegetação a se empregar. Estes conceitos serão discutidos no estudo de caso, obra executada pela concessionária que administra a rodovia.

\section{OBJETIVOS}

O objetivo geral deste trabalho foi estudar técnicas de controle de erosão visando reduzir o impacto ambiental através da vegetação adequada e o uso da Bioengenharia dos solos.

Visando alcançar os objetivos gerais são propostos os seguintes objetivos específicos. Realizar levantamento fotográfico e identificar tipos de erosão às margens da rodovia da PR-317 entre 
Floresta e Peabiru; Identificar fatores causadores da erosão; Propor e identificar técnicas para o controle da erosão.

\section{MÉTODO DE ANÁLISE}

Utilizando-se como fonte de pesquisa livros, artigos e dissertações, a pesquisa possui caráter técnico. $\mathrm{O}$ trabalho com intuito de analisar áreas afetadas causadas por erosões, fez uso de conceitos atuais sobre a contenção e combate à erosão através de novas tecnologias.

Por meio da análise das regiões de visitas em campo na PR-317, foi possível levantar dados reais dos locais erosivos caracterizando sua forma e tipo de agente causador e apresentar a técnica empregada pela empresa responsável fornecendo respaldo e solidez ao conteúdo dessa pesquisa.

A obra analisada é de grande porte e impacto ambiental, pois se trata de obras de duplicação que necessita de movimentação de terra que gera grande modificação do terreno natural. Desta forma, foi importante demonstrar técnicas empregadas para recuperar a vegetação e combater a erosão.

Os estudos do controle da erosão foram realizados considerando as características do solo da PR-317 nas regiões entre Floresta e Peabirú, situadas no Estado do Paraná (Figura 1).

O projeto em estudo localiza-se no Terceiro Planalto do Estado do Paraná, na transição entre o Planalto de Apucarana e o Planalto de Campo Mourão (CARDOSO, 2013).

Ao longo de todo o trecho, o solo predominante é o latossolo vermelho, de textura argilosa, profundo, muito fértil, capaz de suportar grande atividade agrícola. Os solos desta região foram desenvolvidos a partir da meteorização de rochas do derrame do basalto. 0 solo quando em estado natural, não apresentam grandes perigos quando relacionados a erosão, no entanto, quando há atividade de obras intensas, os locais se tornam mais suscetíveis ao fenômeno erosivo, sendo necessário realizar uma cobertura vegetal adequada e implantação de dispositivos de drenagem após os serviços de terraplenagem (EMPRESA (A)).

A região em estudo situa-se entre as isotermas anuais de $19^{\circ} \mathrm{C}$ à $20^{\circ} \mathrm{C}$ e está localizada no paralelo 24오 sendo que, este paralelo desempenha papel delimitador climático no Estado. Nas latitudes inferiores encontram-se as maiores temperaturas, enquanto temperaturas mais amenas situam-se além dessa latitude. Esta "separação" climática proporciona na região a maior variação térmica do Estado (PARANÁ, 1987).

Foi realizada uma quantificação quanto aos pontos identificados e cada tipo de agentes causadores como: declividades, concentração de escoamento superficial, compactação do solo, existência de ravinas, voçorocas e deslizamento de terras.

Um dos fatores a ser considerado para conter a erosão é estabelecer critérios para o uso, considerando capacidade do solo em áreas rurais e aplicar técnicas para recuperar áreas afetadas de forma a conter a erosão em áreas urbanas. A aplicação de métodos adequados de movimentação de

terra reduzindo os efeitos de erosão está presente na legislação referente ao uso e ocupação do solo (COELHO, 2001). 
A funcionalidade do pavimento pode ser afetada pelo desequilíbrio dos cursos d'água que escoam sobre os taludes e encostas, provocando elevados índices de erosão. Um dos métodos de prevenção

é conduzir a água por meio de condutores de dissipação de energia a fim de reduzir a velocidade de escoamento e encaminhá-la para o ponto mais distante possível (COELHO, 2005).

Outra alternativa, a fim de garantir sua estabilização, é a utilização da vegetação adequada, na qual oferece o reforço das raízes e proteção mecânica, beneficiando a estabilidade dos taludes e encostas (ARAÚJO et al., 2012).

Figura 1: Esquematização do mapeamento da região em estudo.

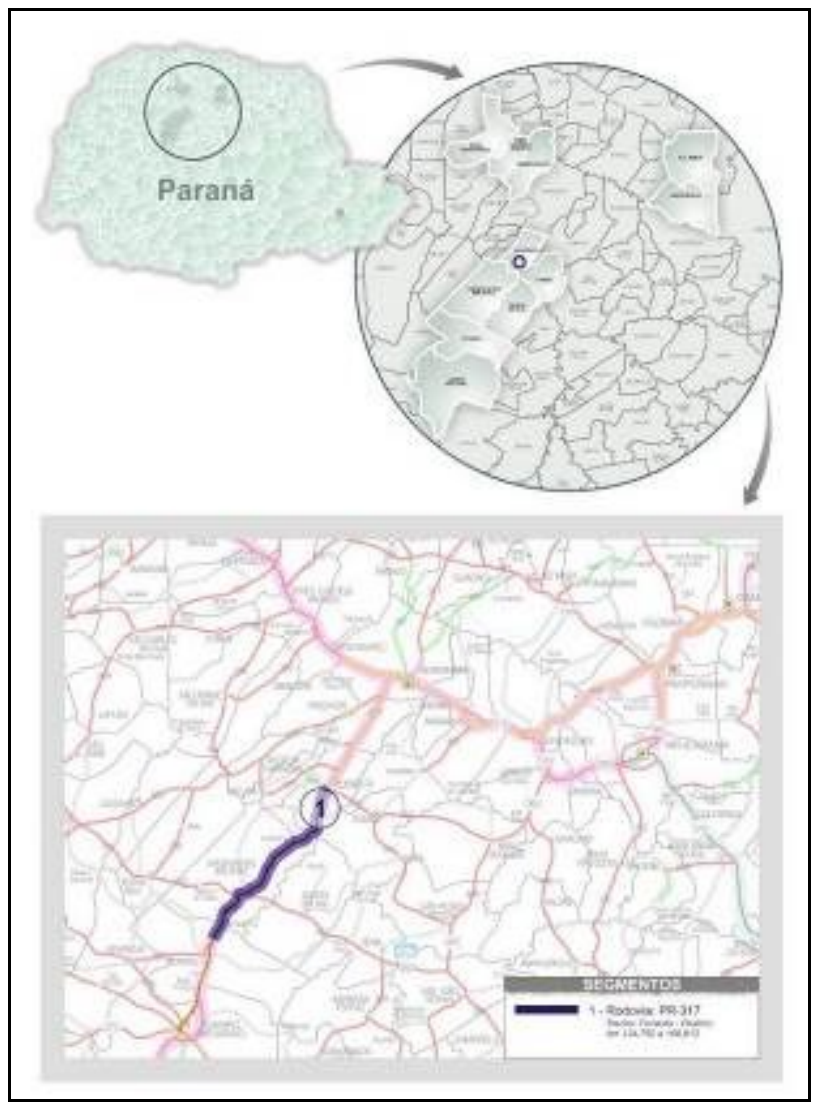

Fonte: Empresa (A)

\section{RESULTADOS}

A região analisada apresentava processos erosivos já desenvolvidos e, em alguns casos agravantes. Os processos foram desencadeados após o início da retirada da vegetação nativa. Algumas técnicas foram empregadas e demonstraram a eficiência e eficácia ao combate à erosão. 
Por meio do levantamento fotográfico, foi levantada áreas degradadas pelo processo de erosão identificando sua causa e apresentado técnicas de controle para corrigir e recuperar o local, que serão apresentadas nas imagens a seguir.

Na figura 2 é apresentada uma erosão tipo laminar, que de acordo com Carvalho et al., (2001), ela ocorre na superfície do solo de maneira uniforma, localizada no Km 162+000. Este tipo de erosão foi provocado por um conjunto de fatores: pelo volume intenso de chuvas nessa área, pela falta de sarjeta no bordo da rodovia que pudesse direcionar a água ao bueiro e assim reduzir o efeito da erosão e invadir a área rural. Outro fator agravante foi a má execução de curvas de nível nestas áreas, capazes de conter a água e diminuir a velocidade de escoamento impedindo o carregamento do material do solo.

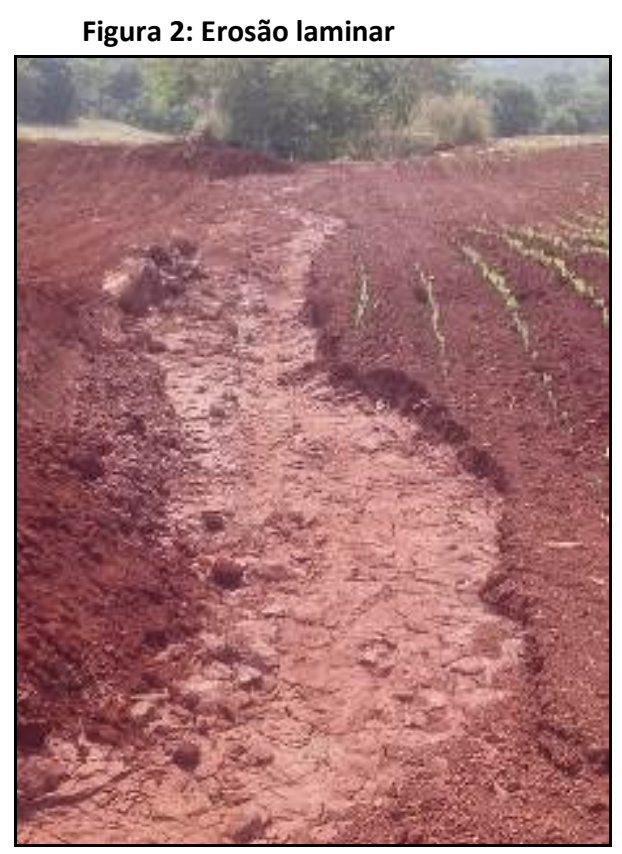

Fonte: ELABORAÇÃO PRÓPRIA

Nas figuras 3(A) e 3(B), entre os $\mathrm{Km} 155+00$ e 156+000, foi identificada a erosão em sulcos, segundo Carvalho et al., (2001), são pequenos canais abertos de pequena profundidade nos taludes. Para a construção do viaduto foi realizado um reaterro em sobre o pavimento existente favorecendo o processo erosivo. Esses sulcos foram observados durante o processo construtivo. A técnica empregada para conter a erosão foi processo de hidrosemeadura que segundo Galas (2006), são compostas por fertilizantes, sementes e resíduoes vegetaisque alteram seu ph com uso de bomba hifráulica que serão apresentadas nas figuras $8(A)$ e $8(B)$.

Figura 3: (A) e (B) Erosão em sulcos em taludes de corte

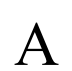

B 


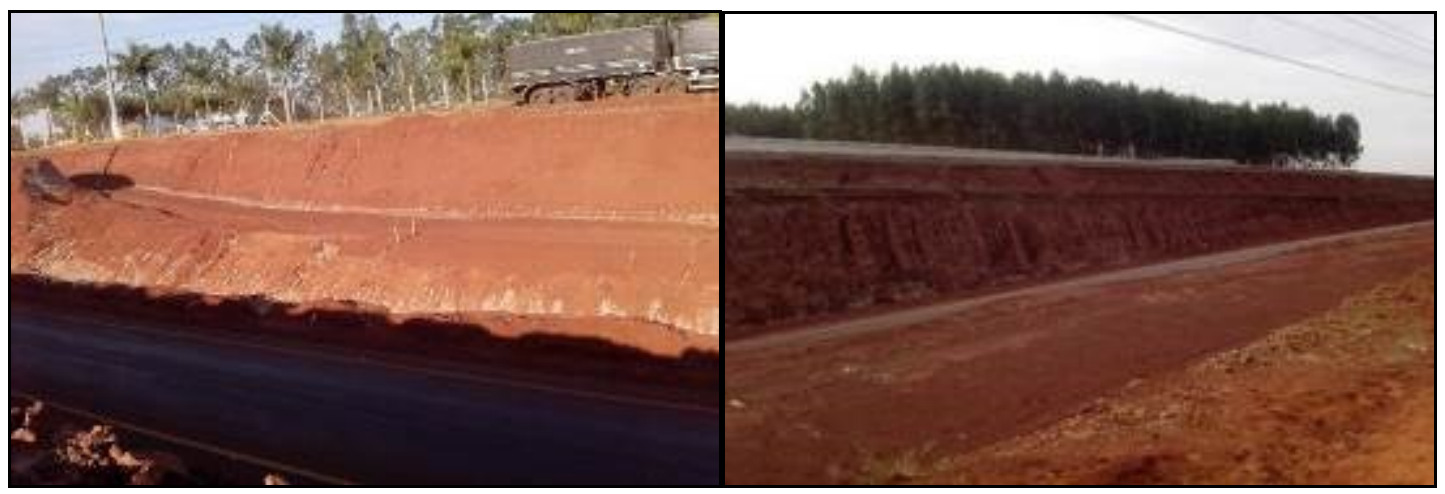

Fonte: ELABORAÇÃO PRÓPRIA

Na figura 4, no Km 148+000 é representado outro exemplo de erosão em sulcos, ocorridos durante o processo construtivo anterior ao controle de erosão. Fato gerado pelo uso do solo ao implantar a pista nova, permitindo que a água da chuva escoe as superficie do talude formando sulcos. Como técnica de controle, foi utilizada aplicação da hidrosemeadura por permtir rápido crescimento, perfilhamento e boa fixação das raízes, promovendo estabilização dos taludes (GALAS, 2006).

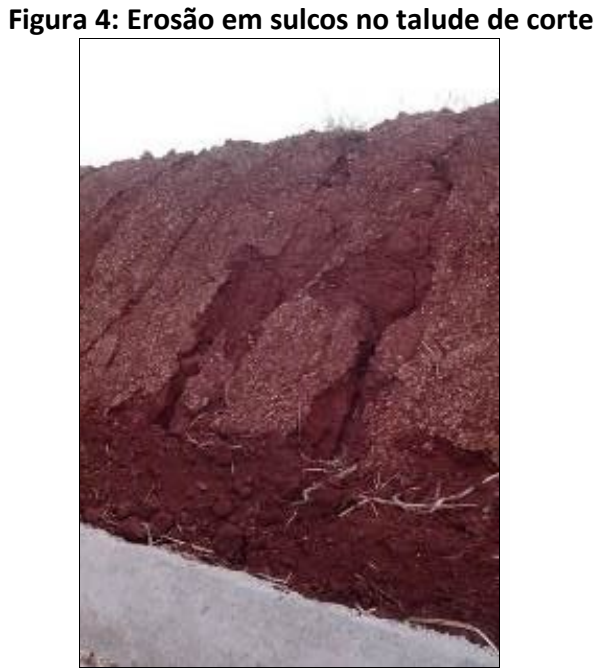

Fonte: ELABORAÇÃO PRÓPRIA

Outro tipo de erosão encontrado foi tipo voçoroca, caso mais agressivo e chega atingir o lençol freatico favorecendo a instabilidade do talude (GALAS, 2006), figura 5(A) e 5(B) localizado no Km 154+000 na área rural.

Esta erosão foi provocada pelo grande volume de água que são coletados pela rodovia e escoados na área rural provocando o carregamento de grande volume de material do solo ao longo de vários anos. A técnica utilizada pela concessionária que administra a rodovia, foi a execução de um emissário, que coleta todo o volume de água dessa região e direciona, por meios de canais coletores (sarjetas), até dissipadores de energia em degraus. Os dissipadores 
possuem bolcas de lobo a sua jusante que direcionam a água por meio de canais fechados até o rio.

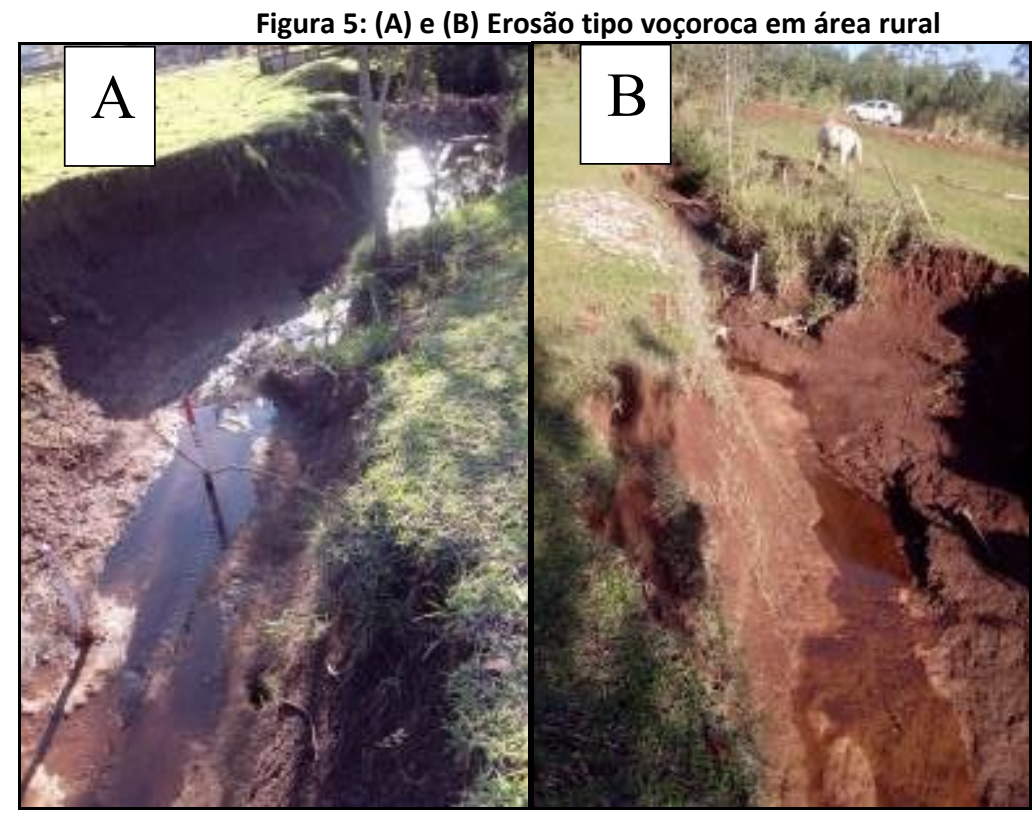

Fonte: ELABORAÇÃO PRÓPRIA

Nas figuras 6(A) e 6(B) representam casos do tipo de voçorocas quem assim como no caso anterior (figura $5 \mathrm{~A} \mathrm{e} \mathrm{B}$ ), foi resultado de chuvas intensas ao longo de vários anos removeram grandes quantidades de solo dando origem a cavidades mais profundas deixando as raízes expostas (BERTONI e LOMBARDI NETO, 1995). Esta erosão foi localizada no Km 162+000 com extensão de aproximadamente $600 \mathrm{~m}$, ocasionada pela falta de sistemas de drenagem adequado às margens da rodovias, como por exemplo, sistemas coletores da água das chuvas (sarjetas) que permitem o direcionamento adequado aos dispositivos de caixas de contenção e bueiros. A falta de curvas de nível do solo contribuiu na intensificação no processo da erosão. Como técnica de contensão foi realizada a execução de todo sistema de drenagem da rodovia prevista em projeto, com a implantação de bacias de contenção, sarjetas nos bordos e a construção de curvas de nível capaz de reduzir a velocidade da água e conter o volume de chuvas.

Figura 6: (A) e (B) Erosão tipo voçoroca em área rural 


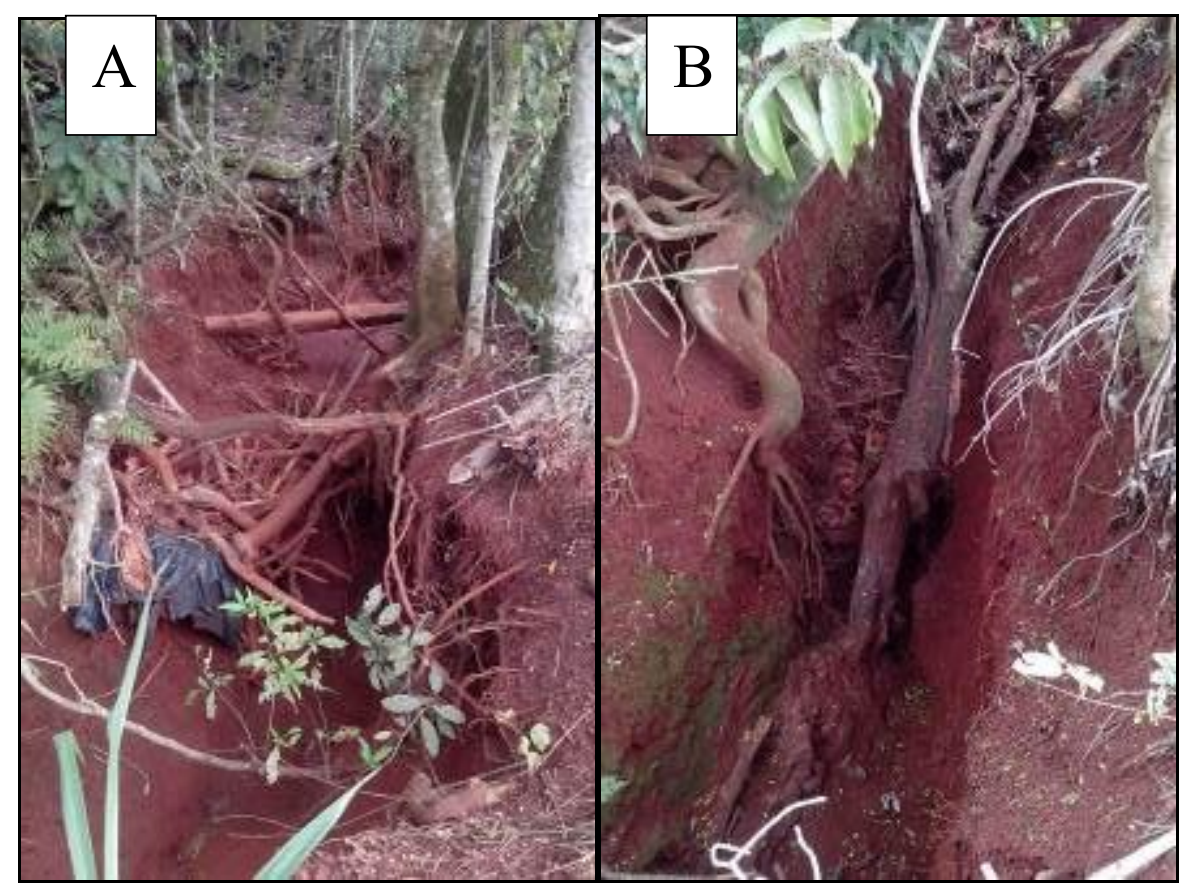

Fonte: ELABORAÇÃO PRÓPRIA

Ao longo do trecho, foram encontrados 5 pontos com erosão e identificado as causas que possibilitou o desenvolvimento desses fatores. Na figura abaixo, é ilustrado o mapa geral da localização dos pontos com erosão ao longo do trecho.

Figura 7: Mapa geral da localização dos pontos com erosão 


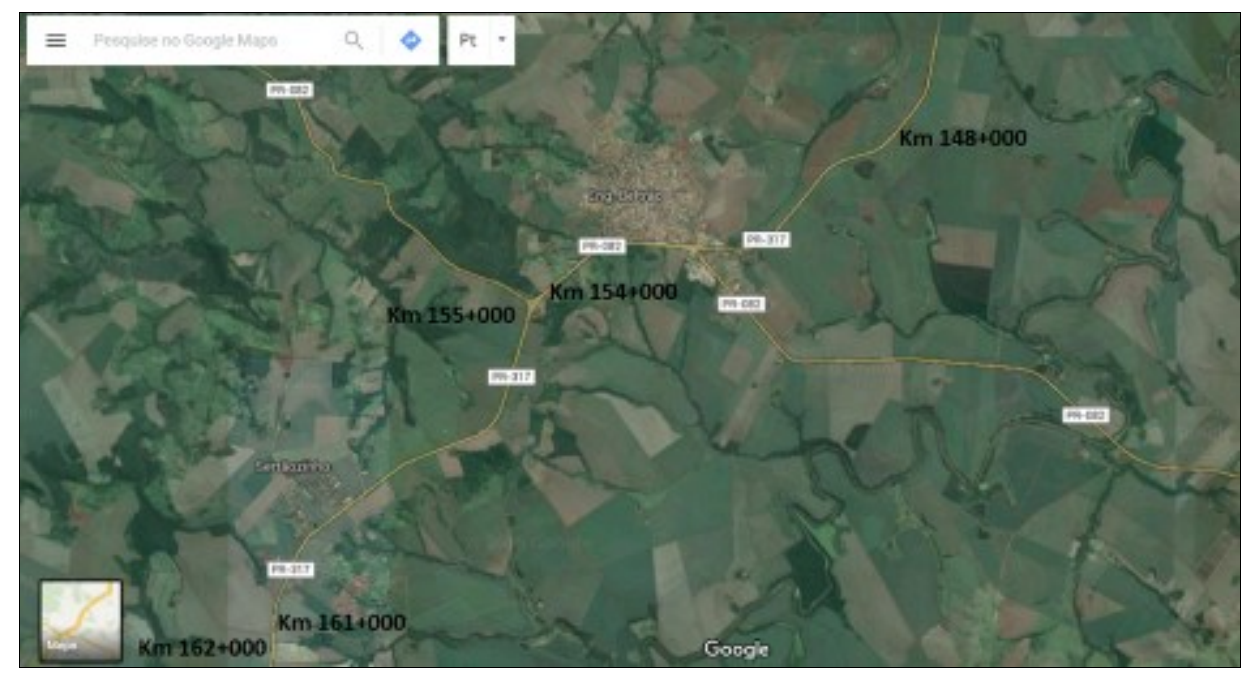

Fonte: ELABORAÇÃO PRÓPRIA

\subsection{TÉCNICAS UTILIZADAS PARA CONTROLE DA EROSÃO}

Nas imagens a seguir, serão apresentadas algumas técnicas empregadas nos problemas encontrados referente ao objetivo principal deste trabalho.

Nas figuras $8(A)$ e $8(B)$ são representados os taludes após a aplicação da hidrosemeadura dos problemas encontrados nas figuras $3(\mathrm{~A})$ e $3(\mathrm{~B})$. Desta forma, a cobertura vegetal possui misto de sementes de gramíneas e leguminosas que possuem rápido crescimento e garante a estabilidade do talude possibilitando fixação do solo (GALAS, 2006).

Figura 8: (A) e (B) Taludes com aplicação da hidro-semeadura 

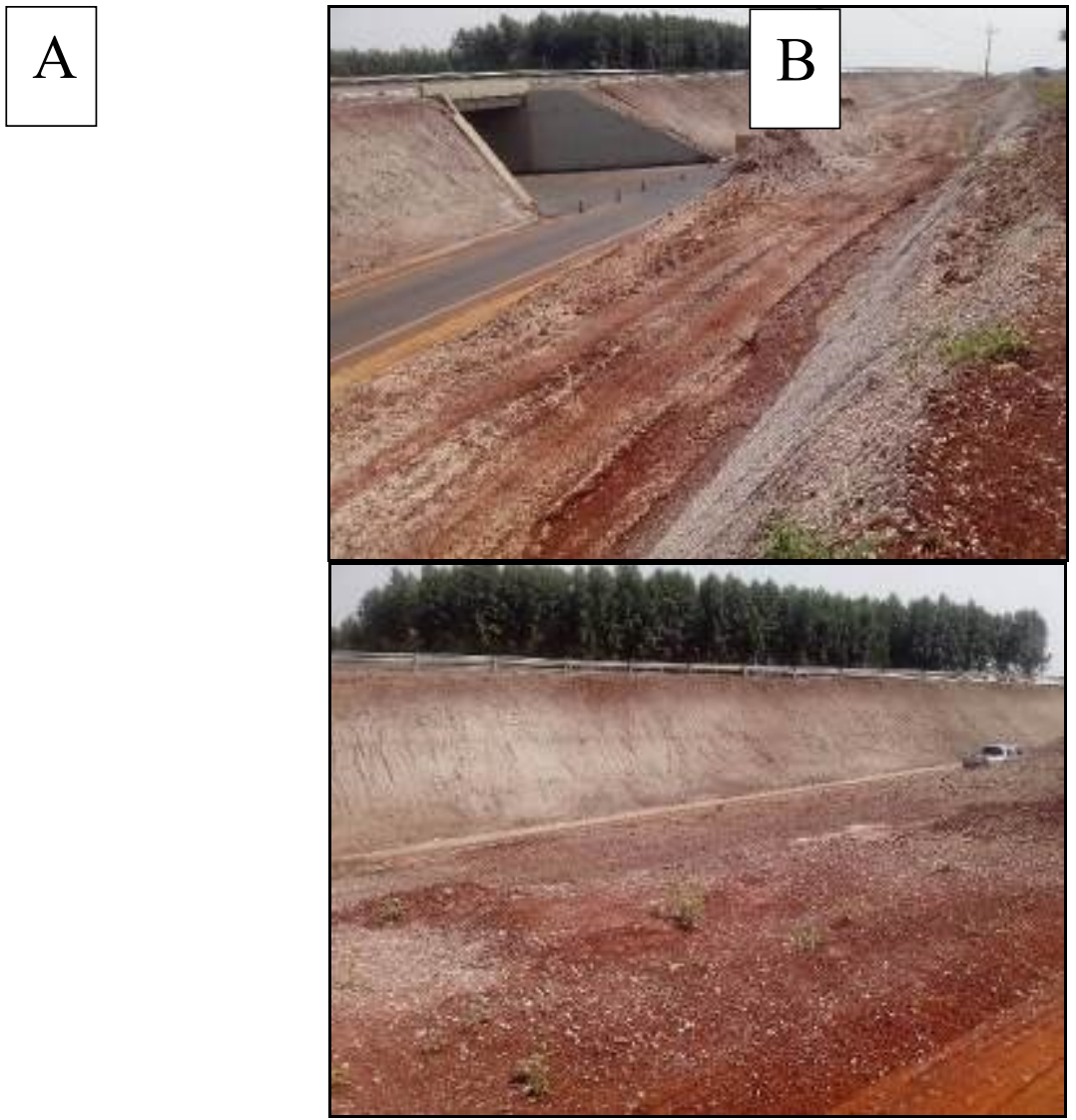

Fonte: ELABORAÇÃO PRÓPRIA

O controle realizado para eliminar as voçorocas encontradas no $\mathrm{Km} 154+000$ pode ser visualizado nas figuras 9(A) e 9(B). Como técnica, foi realizada a execução de um emissário que direciona toda a água coletada no pavimento ao curso do rio. Para isso, foram utilizados dissipadores de energia em degraus (figuras 4 (A) e 4(B)), direcionando a água através de tubos relocados nas voçorocas aterrando o local.

Figura 9: (A) e (B) Reaterro da área prejudicada pelo processo de erosão

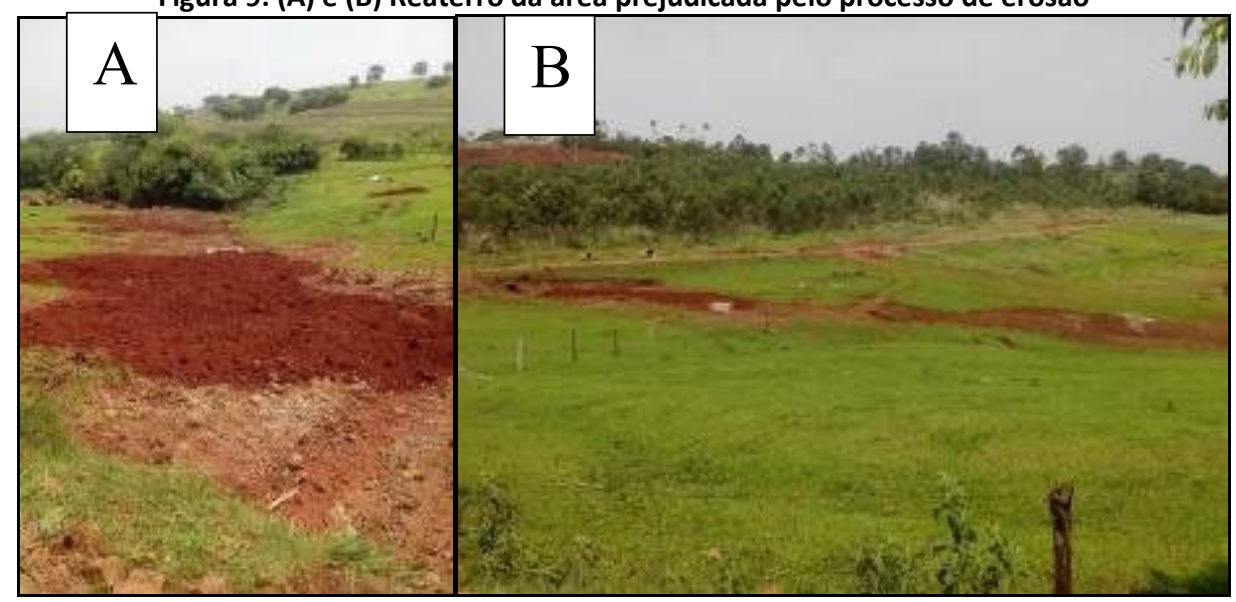

Fonte: ELABORAÇÃO PRÓPRIA 
Nas figuras $10(A)$ e 10 (B) é representado o dissipador de energia com descida d'água em degrau executada para solucionar o problema encontrado na erosão. $O$ dissipador de energia em canal aberto, possui como função captar a água da sarjeta e conduzi-las para bacia de amortecimento e diminuir a velocidade da queda d'água evitando o carregamento de partículas do solo de modo a reduzir efeitos de erosão em áreas próximas (DNIT, 2006).

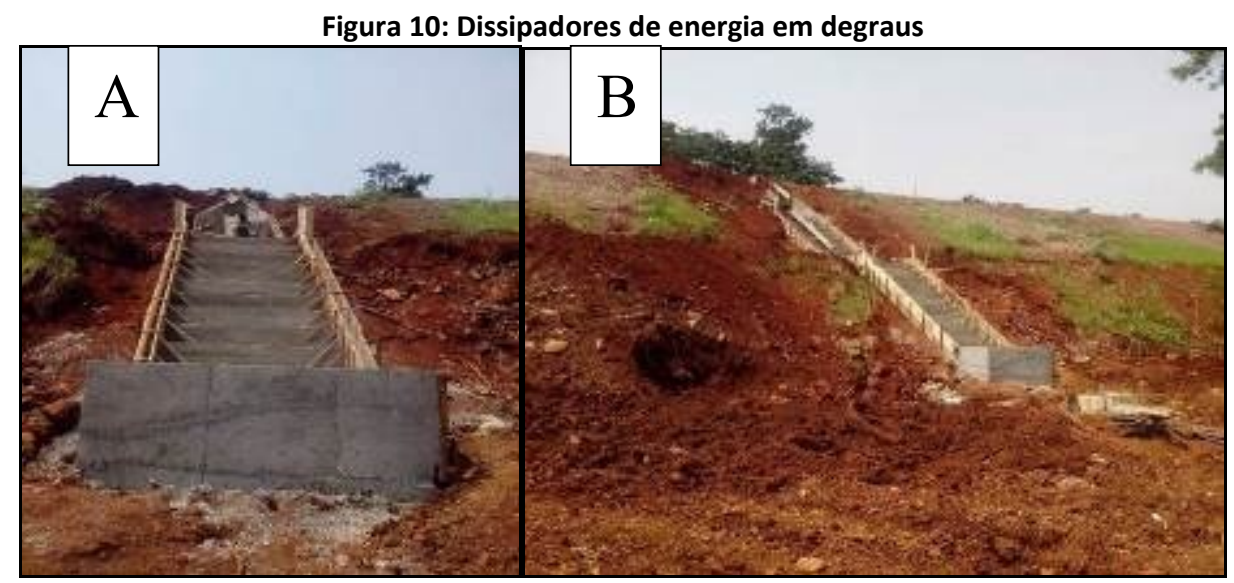

Fonte: ELABORAÇÃO PRÓPRIA

Ao longo do trecho no $\mathrm{Km}$ 159+000 nas figuras 11(A) e 11(B) foi utilizado a implantação em leivas de grama, um processo manual de aplicação da facilidade de obtenção de grama apropriada (CARVALHO et al., 2001).

Figura 11: (A) e (B) Aplicação de placas em leivas

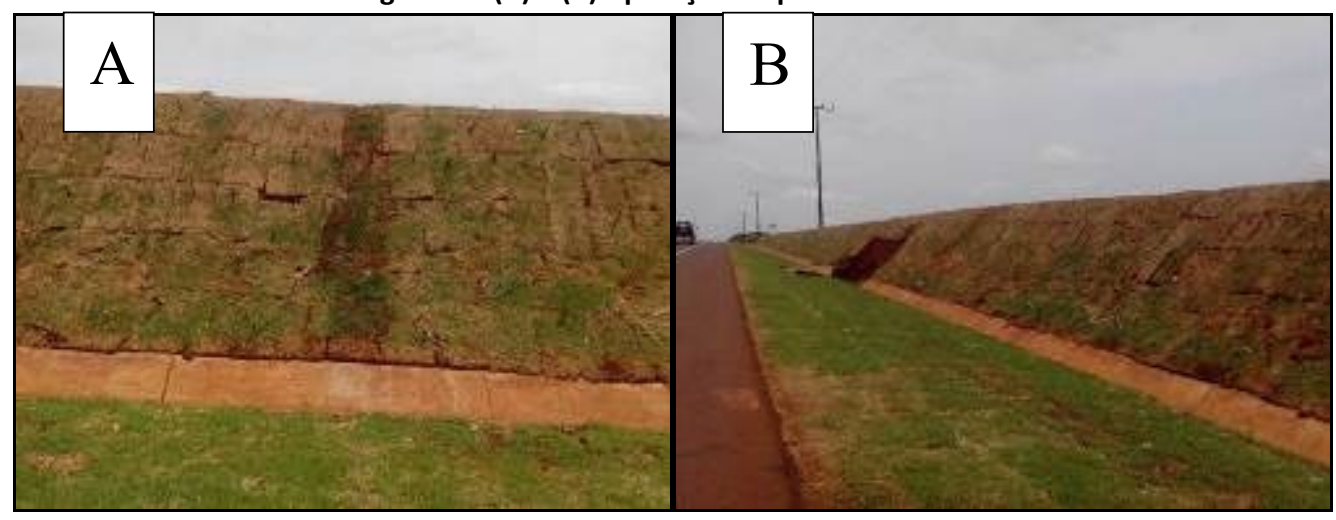

Fonte: ELABORAÇÃO PRÓPRIA 
No Km 149+000, nas figuras 12(A) e 12(B) foi executada a caixa de infiltração em série, que funcionam como dissipadores de energia que coletam a água das sarjetas a montante e transposição de talvegues reservando-a evitando que a água se extravase ao pavimento É importante calcular a área de drenagem do pavimento para verificar se as bacias de contenção são capazes de suportar a vazão e infiltrar a água impedindo que ela se extravase.
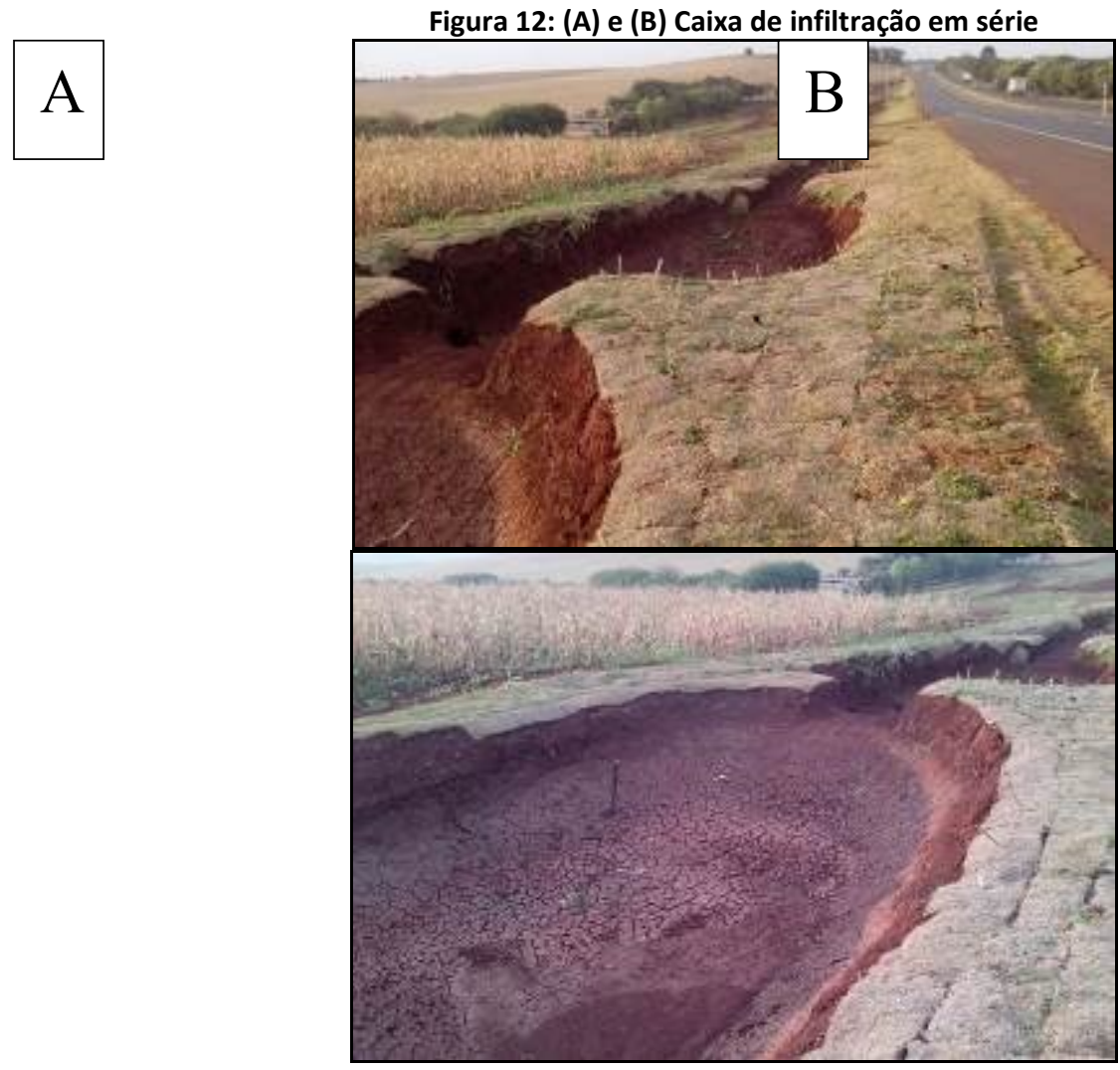

Fonte: ELABORAÇÃO PRÓPRIA

\section{CONCLUSÃO}

Assim foi possível concluir neste estudo que a ação antrópica é um dos principais fatores que auxiliam no processo erosivo devido as obras de engenharia e, de acordo com as Salomão e Iwasa (1995), a água da chuva, topografia e cobertura vegetal são os agentes de intensidade de erosão. Estudar técnicas de controle da erosão é uma etapa importante para diagnosticar corretamente o problema para recuperar áreas afetadas e reduzir o grau de impacto ambiental através da cobertura vegetal adequada e implantação de sistemas de drenagem correto que coletam a água direcionam-na em dispositivos corretos sem agredir o solo.

A vegetação tem importante função de manter o solo do talude estável por meio da fixação mecânica das raízes e tornar o solo permeável. 
Os métodos mais utilizados ao longo do trecho da PR-317, foi a utilização de cobertura vegetal por hidro-semeadura e leivas de grama e, nos casos mais graves, o emprego de emissário e dissipadores de energia nos locais onde houveram erosões tipo voçoroca.

Ao analisar o estudo de caso, foi possível observar que o emprego da vegetação não somente traz estabilidade ao talude e combate a erosão como traz uma estética mais agradável e desenvolvimento sustentável.

\section{REFERÊNCIAS BIBLIOGRÁFICAS}

ARAÚJO, N. C.; et al. Resposta Técnica. Disponível em: <http://sbrt.ibict.br/upload/sbrt1254.pdf>.

BERTONJ, J.; LOMBARDI NETO, F. A. (1995). Conservação do solo. 3ed. São Paulo: Ícone, 1995. 355p.

COELHO, Arnaldo Teixeira. Efeitos da vegetação na estabilidade do solo e de taludes.In: XIII Curso sobre erosão e controle de sedimentos, 2005, Belo Horizonte.

CARDOSO, Priscila M. Análise das características físicas e ambientais da bacia do córrego tucanos em Londrina-PR. 2013, 87 f.Trabalho de conclusão de curso - Graduação em Geografia, Universidade Estadual de Londrina, 2013.2 Disponível em: <http://www.uel.br/cce/geo/tcc/153_analisedascaracteristicasfisicaseambientaisdabaciadocorregotuca nosemlondrinapr_2013.pdf>.

Departamento Nacional De Infra-Estrutura De Transportes. DNIT. Álbum de projetos - Tipo de dispositivos de Drenagem. 2006.

GALETI, Paulo Anestar. Conservação do solo: reflorestamento e clima. 2 ed. Campinas: Instituto campineiro de Ensino Agrícola, 1979.

GONÇALVES, J. L. M. Conservação do solo. In. GONÇALVES, J. L. M.; STAPE, J. L.

(Ed). Conservação e cultivo de solos para plantações florestais . Piracicaba: IPEF, 2002.

NARUNA, Dias Galas. Uso de vegetação para contenção e combate à erosão em taludes. Universidade Anhembi Morumbi - Trabalho de Conclusão de Curso. São Paulo, 2006.

PARANÁ. Secretaria de Estado da Agricultura e do Abastecimento. Instituto de Terras, Cartografia e Florestas. Atlas do Estado do Paraná. Curitiba: Governo do Estado, 1987.

SALOMÃO, Fernando Ximenes T; IWASA, Oswaldo Yujiro. Curso de geologia aplicada ao meio ambiente. São Paulo; ABGE E IPT, 1995. 